\title{
Effect of Low ALR on the Spray Characteristics of a Pressure-swirl Duplex Nozzle
}

\author{
R. A. Dafsari ${ }^{1}$, R. Chandrahasan ${ }^{1}$, C. Ahn ${ }^{2}$ and J. Lee ${ }^{3 \dagger}$ \\ ${ }^{1}$ School of Mechanical System Engineering, Chonbuk National University, Jeonju, Republic of Korea \\ ${ }^{2}$ Aerospace R\&D Center, Hanwha Aerospace Seongnam, Gyeonggi-do, 13488, Republic of Korea \\ ${ }^{3}$ Faculty of Mechanical System Engineering, Chonbuk National University, Jeonju, Republic of Korea \\ †Corresponding Author Email: leejk@jbnu.ac.kr
}

(Received April 6, 2020; accepted October 5, 2020)

\begin{abstract}
The objective of this study is to investigate the effect of the air-to-liquid ratio (ALR) in a low range on the characteristics of the spray issuing from a pressure-swirl duplex nozzle. In this study, the pressure-swirl duplex nozzle was used as an atomizer with non-swirl shroud air. The shroud air was radially discharged inward across the nozzle face to avoid the contamination of the nozzle tip. Jet A-1 fuel was used as the working fluid. The analysis of the spray characteristics was carried out by using a phase Doppler anemometry (PDA) system and a laser based planer imaging system. The flow rate, discharge coefficient, spray structure, spray cone angle, velocity and drop size distributions were analyzed. The results show that the discharge coefficient of the pilot nozzle is higher than that of the main nozzle and the combined pilot and main nozzles. The spray angle tends to decrease almost linearly with increasing ALR. The shape of the spray gradually changes from a hollow cone to a full cone with increasing ALR, as revealed in the axial velocity distributions with an increase in the axial distance. The weighted mean SMD (WMSMD) increases by 1.2 as the ALR increases, but thereafter, it decreases again.
\end{abstract}

Keywords: Air to liquid ratio; Duplex nozzle; Laser diagnostics; Multiphase flow; Spray droplet size.

\section{INTRODUCTION}

Atomization is defined as the conversion process of bulk liquid into small droplets. A device known as an atomizer is used to perform this task. Various types of atomizers are being frequently used in industrial fields, a pressure-swirl atomizer is one of those with widespread applications, in the aerospace, industrial and agricultural fields, due to its simple geometry and efficient performance. Pressure swirl nozzles convert the injection pressure into kinetic energy to reach a high relative velocity between the injected liquid and the surrounding air. This particular type of nozzle can be employed as an injector in the gas turbine combustor. The prime objective of fuel atomization in gas-turbine is to enhance the rate of heat and mass transfer during combustion which can be achieved with minimizing the size of issuing droplets. Combustion efficiency is also greatly dependent on the performance of atomizers. Poor atomization degrades ignition performance and increases the pollutant gas products. A typical pressure swirl nozzle generates a thin annular liquid film - that consequently breaks down into small droplets due to its internal flow with a high swirl intensity benefiting nozzles geometry. Tangential feeding ports deliver the liquid from the nozzle inlet into a swirl chamber and form a high angular velocity to the liquid. Internal swirling flow with high centrifugal force causes the formation of an air-cored vortex in the swirl chamber, and the liquid travels from a nozzle orifice to form a hollow conical spray. The presence of an air-core reduces the effective flow area at the discharge orifice by occupying a portion of it. This affects the hydraulic behavior of the nozzle, namely the volumetric flow rate. Atomization characteristics are dependent on atomizers geometry, injection condition, and fuel physical properties (Vashahi and Lee 2018; Dafsari, Lee, et al. 2019a; Dafsari et al. 2017; Geng et al. 2020). The main drawback of the simplex pressureswirl nozzle is that the turn-down ratio of the liquid flow is not enough to provide efficient combustion (Chen et al. 1990). This proposition makes it difficult to operate over a wide range of flow conditions with a single atomizer. Increasing the flow number of the atomizer enables operation at a high flow rate at reasonable injection pressure. However, the atomization quality at low flow-rate conditions is compromised. To overcome this problem, the duplex nozzle (also known as a dual-orifice nozzle) was developed. The duplex nozzle consists of two nozzles, one placed inside another. The outer nozzle is called the main nozzle, and the inner nozzle is 
called the pilot nozzle. The pilot nozzle is used for a low flow rate, and the main nozzle is used for a high flow rate. When the duplex nozzle works in combined nozzle mode, it usually has a flow rate three times higher than that of the simplex nozzle, which reduces the mean drop size at low injection pressure. This configuration makes the duplex nozzle more functional for conditions with pressure variation. However, the main drawback of the duplex nozzle is that the spray cone angle in the combined nozzle is smaller than that of the pilot nozzle. This is due to an increased ratio of the inlet port area to both swirl chamber diameter and discharge orifice diameter in the combined mode, which decays the spray cone angle (Lefebvre et al. 2017). To overcome this problem, a small amount of air is needed to apply on the nozzle face. This so-called shroud air protects nozzle tip from contamination and overheating by the flame by limiting the spray cone angle. Clare et al. (1964) reported the influence of various swirling and nonswirling shroud air on the mean drop size and found that swirling shroud air has better atomization quality than non-swirling shroud air. The non-swirling shroud air leads to a narrow spray cone angle, and the swirling shroud air tends to widen the spray cone angle because of the radially outward direction of the gas movement. An experiment was performed by Li and Tankin (1991) on the spray characteristics with and without swirling air flows. They observed an improved quality of air and fuel mixing with strong swirling airflow, which ultimately facilitated the combustion process.

The quality of atomization is determined by many properties, such as flow rate, discharge coefficient, spray structure, spray cone angle, velocity, and SMD distribution. When a shroud air is applied, the airtoliquid ratio (ALR) is a significantly influential parameter involving in the characteristics of atomization and combustion. It defines the amount of air needed to burn a specific fuel. Numerous researchers have reported the importance of the ALR in analyzing spray characteristics and their effect on spray characteristics. For example, Evers (1994) performed an experiment with a simplex pressureswirl nozzle to characterize the transient spray. During the experiment, several parameters, such as the ALR, ambient air pressure surrounding the spray, fluid pressure upstream of the nozzle, and amount of swirl in the fluid leaving the nozzle, were varied. He found that the ALR and geometry of the nozzle have a great influence on the characteristics of the spray. Lee et al. (2002) indicated that an increase of ALR results in an expansion of radial growth rate, reducing the number of clusters and also enhancement of the disintegration of the liquid jet/sheet. Ferreira et al. (2009) modified a twin-fluid nozzle to conduct an experiment determining the significance of the main involving parameters that characterize the issuing spray generated from the injector. Their study showed that the importance of ALR on the liquid atomization phenomena. Similarly, Roesler and Lefebvre (1989) examined the behavior of an aerated-liquid nozzle under a bubbly flow operational condition. They found that the mean drop size rapidly decreased with an initial increase in the ALR. However, a slight decrease was observed when the ALR was further increased. Mansour and Chigier (1990) observed that the SMD of the spray decreased with increasing ALR. Lee (2008) studied the effect of ALR on turbulent structures in swirling flow and reported that increasing the ALR caused a decrease in the SMD and showed better atomization.

The above reviews show that there have been adequate investigations in the literature on the effect of ALR on the spray characteristics of simplex pressure-swirl nozzles. However, little work has been done in terms of the pressure-swirl duplex nozzle to date. Therefore, it is essential to investigate the physics of pressure-swirl duplex atomization to gain a better understanding of the effect of ALR on the spray characteristics. Most studies to the date focused on higher range of ALR aiming for higher turbulent flow, however, the current study is directed to a lower range of ALR which illustrates that a very small amount of air introduced to the liquid can have unexpected trend. Thus, the main objective of this study is to investigate the effect of low range ALR spray structure of the pressure-swirl duplex nozzle.

\section{EXPERIMENTAL METHODOLOGY}

The experimental setup consists of the fuel and air supply system, the fuel injection system including the test nozzle, the laser diagnostic system, and the data acquisition system. A schematic of the experimental setup is shown in Fig. 1.

\subsection{Injection System}

A representative aviation fuel, Jet A-1, was injected from the fuel tank. The fuel tank was pressurized by nitrogen supplied by a $99.99 \%$ pure nitrogen tank. The physical properties of Jet A-1 fuel are shown in Table 1. A BME-1100 Kulite pressure transducer with $\pm 0.1 \%$ accuracy was used to measure the injection pressure. The pressure transducer was positioned at the closest to the nozzle. The generated signal from the transducer was received through a data acquisition device to an in-house NI LabView code and converted into pressure, of which the standard deviation was monitored to be less than $1 \%$. A high-precision mass flow meter KEM-Kuppers VHEF-02 pulse amplifier (standard $0.03 \% \mathrm{Rd}+1.0 \%$ FS) coupled with a Kyongin KM2 flow indicator $( \pm 0.1 \%)$ was set between the fuel tank and the nozzle to measure the flow rate of the fuel. To obtain a constant air flow and to reduce pressure pulsation, air was supplied to the nozzle by an air compressor through an air receiver tank. The rate of air flow was controlled by a KOFLOC 3660 mass flow controller. In addition, a K-type thermocouple was used to measure the temperature of the fuel which was kept constant at $+20^{\circ} \mathrm{C}$.

\subsection{Optical Measurement System}

In this study, planner spray visualization was conducted using a particle image velocimetry (PIV) system. A Nd:YAG double-pulse laser (New Wave Gemini-15 Hz) with a maximum energy of 120 


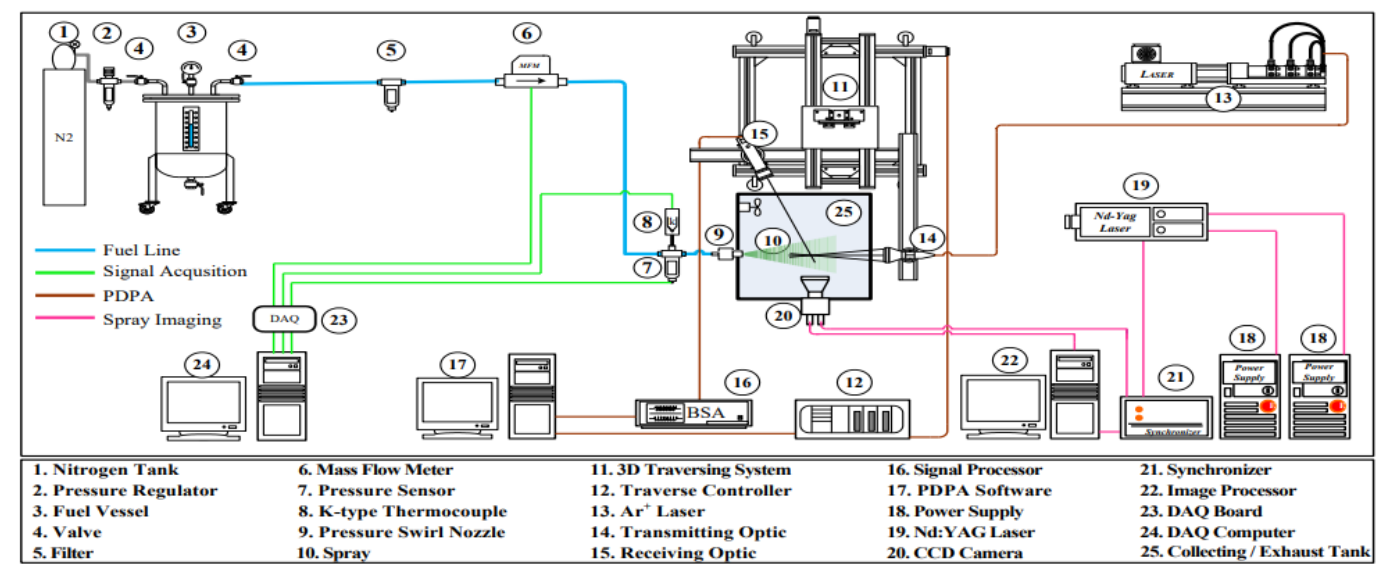

Fig. 1. Experimental Setup.

Table 1 Physical properties of Jet A-1 fuel

\begin{tabular}{|c|c|c|c|c|}
\hline Fuel & Density & Kinematic viscosity & Surface tension & Refractive index \\
\hline Jet A-1 & $\begin{array}{c}814.7 \\
\mathrm{~kg} / \mathrm{m}^{3}\end{array}$ & $1.815 \mathrm{~mm}^{2} / \mathrm{sec}$ & $\begin{array}{c}23.2 \\
\mathrm{mN} / \mathrm{m}\end{array}$ & 1.441 \\
\hline
\end{tabular}

$\mathrm{mJ} /$ pulse was used as the laser source. It produced a laser sheet, with a thickness of approximately $1 \mathrm{~mm}$. Spray images were recorded by a CCD camera (630057 Power view TM plus 4MP). The camera was positioned perpendicular to the laser sheet. A synchronizer was used to unify the timing between the laser source and the camera frame-rate. In each experiment case, 50 spray images were recorded. The measurement of droplet size and velocity were performed using a Dantec conventional 2-D phase Doppler anemometry (PDA) system in a coincide mode. The PDA consisted of an Ar- ion laser, a transmitter, receiver and traverse system. BSA flow software was used to measure the droplet diameter and velocity components. A continuous wave was supplied by a Spectra-Physics 177-G02 air-cooled Argon-ion laser with a laser power of $4 \mathrm{~mJ}$. A beam splitter was used to split the laser beam into two green $(\lambda=514.5 \mathrm{~nm})$ and two blue $(\lambda=488 \mathrm{~nm})$ laser beams with diameter of $1.35 \mathrm{~mm}$. The $40 \mathrm{MHz}$ frequency shift was applied to one of two beams to remove the directional ambiguity. The measurement volume was formed at the intersecting point of the four laser beams. The focal lengths of the transmitting lens and receiver lens were $400 \mathrm{~mm}$ and $600 \mathrm{~mm}$, respectively. The operational condition was set on a sensitivity level of $1000 \mathrm{~V}$, forward scattering angle of $37^{\circ}$, signal gain of $26 \mathrm{~dB}$, Burst detector signal to noise ratio level of $-6 \mathrm{~dB}$, and a maximum measurable droplet diameter of $169 \mu \mathrm{m}$. The PDPA physical calibration was checked frequently by the manufacturer and the optical arrangement and the user input setting were enhanced based on the optimum performance (Dantec-Dynamics 2011; Ralf et al. 2006; Pitcher et al. 1991; Payri et al. 2008; Resagk et al. 2003) and test fuel physical properties (Dafsari et al. 2019c). Even though the PDPA was carefully aligned, the Dantec 2D PDPA basically has maximum errors of 1 and 5\% for the velocity and diameter measurement, respectively (based on the manufacturer's provided data) (Dantec-Dynamics 2011). The phase Doppler method requires no calibration because the measured particle size and velocity are dependent only on the laser wavelength and optical configuration. The PDA measurements of drop sizes and velocities were performed at three different downstream distances from the nozzle tip ( $\mathrm{Z}=5,15$ and $28 \mathrm{~mm})$. In this study, the PDA measurement was based on 10,000 samples per point for a maximum duration of 10 seconds. The experimental conditions of the present study are shown in Table 2.

Table 2. Experimental Conditions

\begin{tabular}{|c|c|c|c|}
\hline $\begin{array}{c}\text { Fuel } \\
\text { injection } \\
\text { pressure, } \\
\Delta \mathrm{P} \text { (bar) }\end{array}$ & $\begin{array}{c}\text { Fuel flow } \\
\text { rate, } \dot{\mathrm{m}}_{\mathrm{L}} \\
(\mathrm{kg} / \mathrm{min})\end{array}$ & $\begin{array}{c}\text { Air flow } \\
\text { rate, } \dot{\mathrm{m}}_{\mathrm{A}} \\
(\mathrm{kg} / \mathrm{min})\end{array}$ & ALR \\
\hline & & 0 & 0 \\
& & 0.0428 & 0.257 \\
& & 0.1078 & 0.6390 \\
& & 0.1543 & 0.9146 \\
& & 0.1960 & 1.1618 \\
& & 0.2327 & 1.3793 \\
& & 0.2535 & 1.5026 \\
& & 0.2633 & 1.5607 \\
\hline
\end{tabular}

\subsection{Nozzle Geometry}

In this study, a pressure-swirl duplex nozzle was used as an atomizer. Generally, this type of nozzle consists of two pressure-swirl atomizers. One is named the pilot nozzle, and the other is named the main nozzle. Both are arranged concentrically, one inside another. Figures 2 shows the structural and 


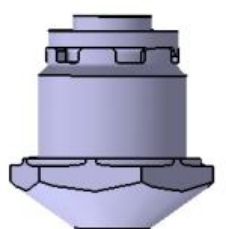

(a) Nozzle

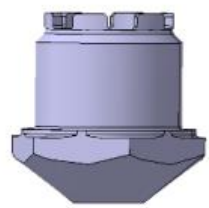

(b) Nozzle body

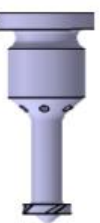

(c) Pilot nozzle

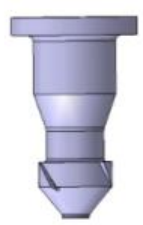

(d) Main nozzle

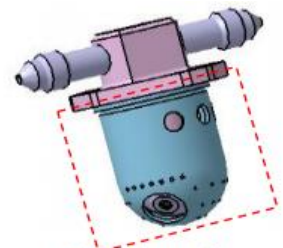

(e) Full nozzle

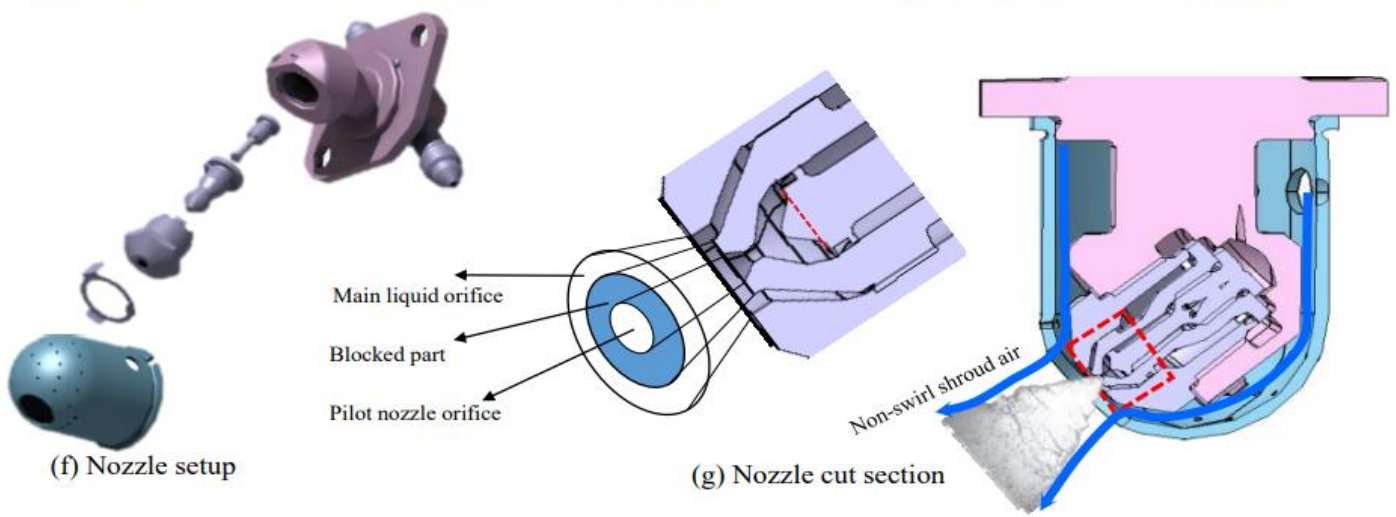

Fig. 2. Nozzle Geometry a) Duplex nozzle, b) Nozzle body, C) Pilot nozzle, d) Main nozzle, e) Full nozzle with the air cap, f) Nozzle setup, g) Nozzle cut-section.

schematic of the nozzle. The area of pilot, main, and pilot plus main nozzle orifices are 2.76, 0.125, 2.89 $\mathrm{mm} 2$ respectively. The pilot nozzle is used for a low flow rate, and the main nozzle is used for a high flow rate. Both nozzles have a separated swirl chamber. A pressure valve is required for this type of atomizer. The purpose of the pressure valve is to separate the liquid flow based on the preset liquid pressure. At low pressure, the liquid flows only through the pilot nozzle, and at high pressure, most of the liquid flows through the main nozzle, and the remaining liquid flows through the pilot nozzle. In this study, the pressure valve was set to open at 6.21 bar. When the liquid pressure reached $6.21 \mathrm{bar}$, it opened the valve, which allowed the liquid to flow through the main nozzle. A change in internal geometry of this nozzle has already been studied (Dafsari et al. 2020).

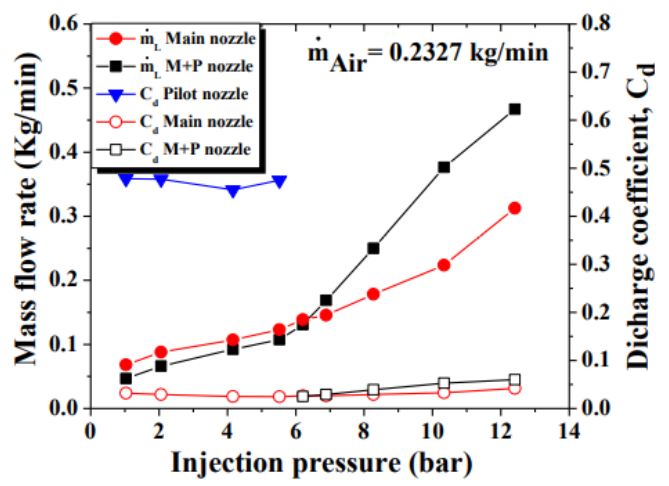

Fig. 3. liquid flowrate and discharge coefficient with liquid pressure variation.

A nozzle shroud cap was used in this nozzle, which discharges air on the nozzle face. It also protects the nozzle from overheating and improves atomization quality, especially at low flow rates. The nozzle shroud cap has six air inlet holes. The nozzle is fixed in a plate, air is supplied to the plate, and then air enters through the air inlet holes of the nozzle shroud cap, as shown in Fig. 2-e. Air is only mixed orifice. The orifice diameter of pilot nozzle is $0.4 \mathrm{~mm}$, and the equivalent diameter of the main nozzle is 1.876 $\mathrm{mm}$. The pilot nozzle has four tangential slots, and the main nozzle has three tangential slots. The width of all tangential slots is $0.3 \mathrm{~mm}$. Figure $2 \mathrm{~g}$ shows the orifice area of the pilot and main nozzle. There is a blocked part between the pilot and the main nozzle from which no fuel comes out.

\section{RESULTS AND DISCUSSION}

\subsection{Flowrate and Discharge Coefficient}

The discharge coefficient is a factor indicating the ratio of the actual to theoretical mass flow rate of the atomizer. The discharge coefficient can be calculated using the equation below:

$$
\mathrm{C}_{\mathrm{d}}=\frac{\dot{\mathrm{m}}}{\mathrm{A}_{0} \sqrt{2 \rho_{1} \Delta \mathrm{p}}}
$$

Where $\dot{m}$ is the liquid mass flowrate, $\mathrm{A}_{0}$ is the area of the orifice, $\rho$ is the liquid density of fuel and $\Delta \mathrm{P}$ is the pressure differential throughout the nozzle. Figure 3 shows the hydraulic performance namely the flow rate and discharge coefficient for different nozzle configurations at different injection pressures. In this case, the experiment was carried out with shroud air fixed at $0.2327 \mathrm{~kg} / \mathrm{min}$. The mass flow rate of the discharged fuel increases significantly with injection pressure. this follows a general trend reported in the literature (Liu et al. 2020). As shown in Fig. 3, the flow rate of combined pilot and main nozzle rapidly increases when the fuel pressure 


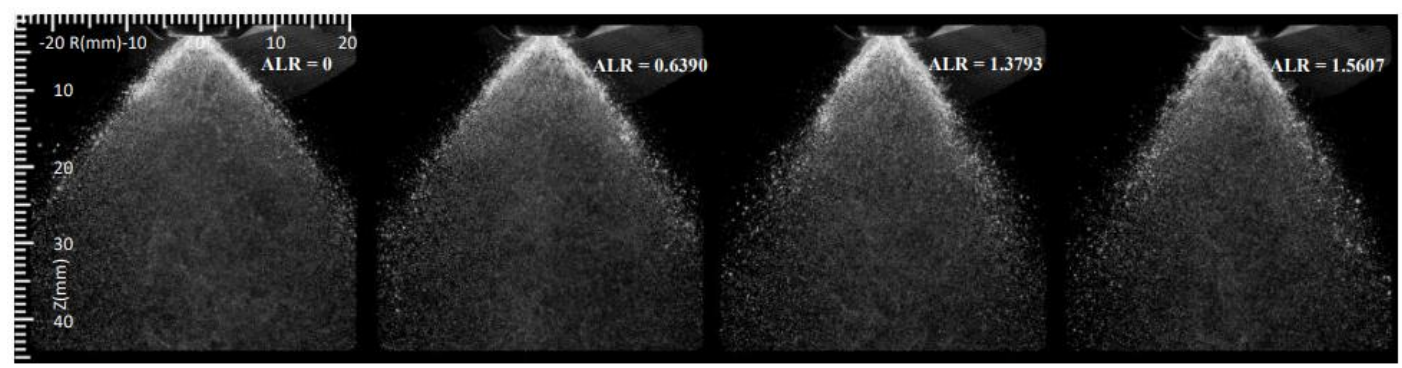

Fig. 4. Spray structure at various ALR under constant fuel flow rate.

reaches 6.21 bar. This is because of the pressure valve, which opens at 6.21 bar and allows the fuel to flow through the pilot and the main nozzle at a time.

In addition, the flow rate of the main nozzle is higher than that of the pilot nozzle but lower than that of the combined pilot and main nozzle. The reason behind this phenomenon is that the flow rate of fuel is highly influenced by the orifice diameter of the nozzle (Som et al. 2011). As the orifice dimeter increases, the flow rate of the fuel also increases. In the case of the discharge coefficient, the pilot nozzle shows a higher value compared to the main nozzle alone and the combined pilot and main nozzle. This phenomenon is also the result of variations in the orifice diameters of nozzles.

Figure 2-g shows the fuel flowing area of the nozzle exit orifice. The fuel exit orifice area of the main nozzle and the combined pilot and main nozzle are much larger than the pilot nozzle alone. The equivalent orifice diameter of the main nozzle is $1.876 \mathrm{~mm}$. However, when the main nozzle only is used, no fuel can flow through the area of the pilot nozzle orifice and blocked part; also, when the combined pilot and main is used, no fuel flows through the area of the blocked part. Thus, the geometry of the pressure-swirl duplex nozzle influences the discharge coefficient. With the increase in injection pressure, a minor variation is found in the profiles of the discharge coefficients of every nozzle configuration and both operating conditions. This indicates that the discharge coefficient of pressure swirl nozzle has a trend independent of liquid flowrate. This agrees well with the report by Dopazo and Ballester (1994). which showed injection pressure does not have any significant influence on the discharge coefficient

\subsection{Spray Structure and Spray Angle}

Figure 4 shows the images of the spray generated from the pressure-swirl duplex nozzle under different ALRs with a constant fuel flow rate of $0.1687 \mathrm{~kg} / \mathrm{min}$. It can be observed from the figure that the spray becomes narrower with an increase in the ALR. With a constant fuel flowrate, an increasing ALR means that the flow rate of air is increasing. Therefore, as the ALR increases, the movement of air is sufficiently developed in the axial direction, which is enough to push the droplets in the spray periphery to the spray center. This causes the spray to be narrower. The phenomenon of the narrowing trend of the spray with increasing ALR can be further understood from Fig. 4 and 5, where the effect of ALR on the spray cone angle is shown. It is simply noticeable that the spray cone angle decreases with increasing ALR. This is due to the entrainment effect and the increased momentum of the air (Chen et al. 1992). When the air pressure increases, the smaller droplets are easily moved to the center of the spray because nonswirling shroud air pushes the droplets in the downward direction, which ultimately causes a reduction in the spray cone angle. When the ALR was changed from 0 to 1.6 , the spray angle change was observed to be $12 \mathrm{deg}$. The shear layer instability can be suppressed by the centrifugal acceleration via the stable stratification of the angular momentum (Shtern 2018). The error bar shown in the figure denotes the standard deviation $( \pm)$ of 10-12 spray cone angle measurements. The largest deviation is found at 2.32 degrees for $A L R=0$.

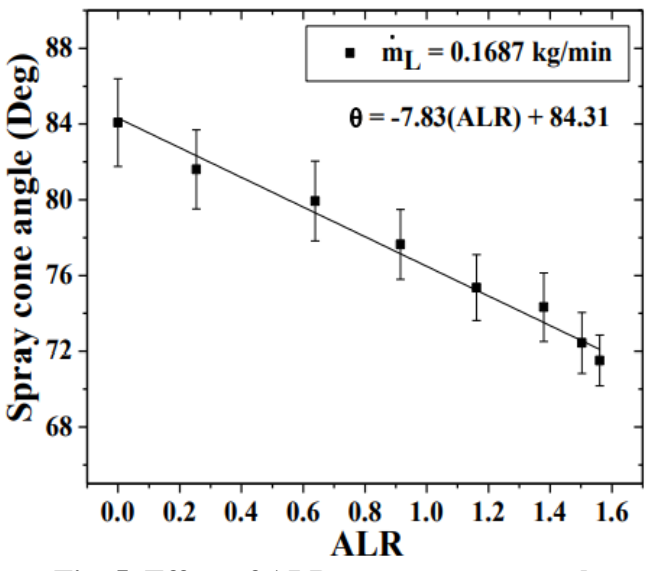

Fig. 5. Effect of ALR on spray cone angle.

\subsection{Velocity Distribution}

Figure 6-a shows the effect of ALR on the axial velocity at a constant fuel flow rate of $0.1687 \mathrm{~kg} / \mathrm{min}$. The axial velocity has small values in the center of the spray and increases gradually with increasing radial distance. This increasing rate is high when the measurement position is near the nozzle tip and decreases further in further axial levels. At the axial distance of $Z=5 \mathrm{~mm}$, which is near the nozzle tip, the axial velocity distribution has two peaks that represent the flow characteristics of the hollow conical swirl spray. The significance of the peaks diminishes further downstream for higher ALR 

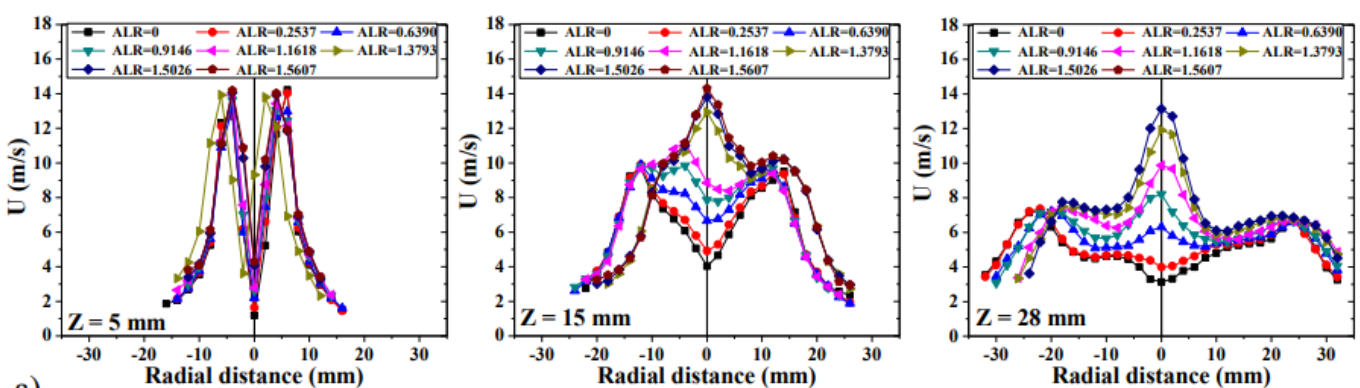

a)
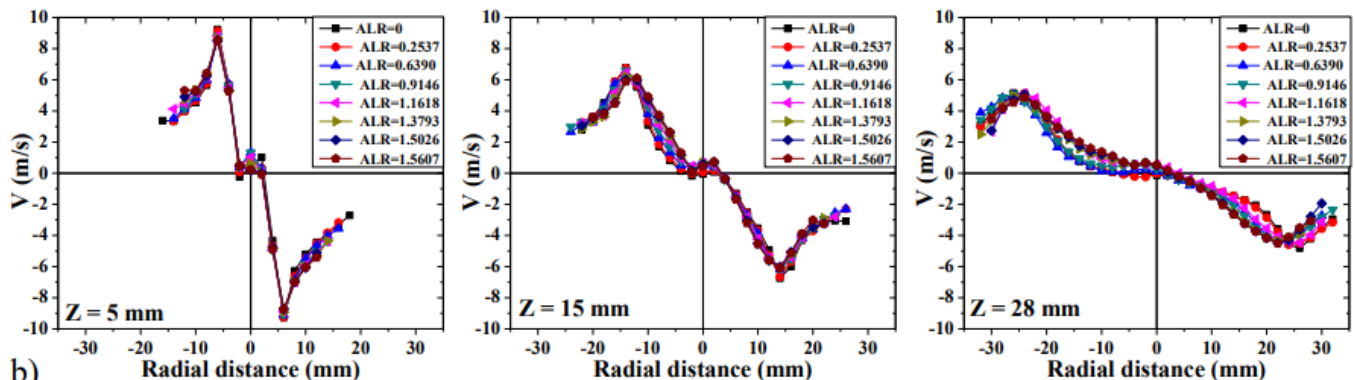

Fig. 6. Droplets mean velocity profile in various axial distances from nozzle tip with variation of ALR (a) top row: Axial velocity (b) bottom row: radial velocity.
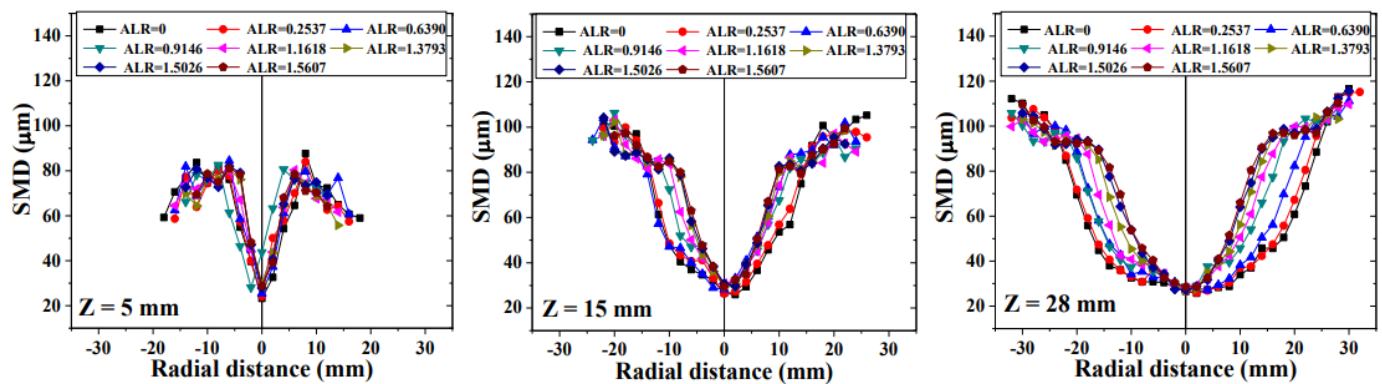

Fig 7. Sauter Mean Diameter profiles with change of ALR and axial distance.

which indicates the spray dispersion level and the effectiveness of the shroud air becoming pronounced by moving more droplets from the spray edges to the spray center leading to a raise in axial velocity in the central spray region (Lasheras et al. 1998). A raise in the mean velocity at the spray edge is observed which can be attributed to higher momentum of larger droplets which is a typical character of swirl spray (Dafsari et al. 2017) and also a momentum exchange between the shroud air and the droplets on the spray outer surface, where the shroud air accelerated the droplets at the periphery (Marchione et al. 2007; Rho et al. 1998; Roudini and Wozniak 2018). Droplets lose their momentum further downstream due to aerodynamic resistance (Dafsari et al. 2017; Chinnaraj and Sadanandan 2020).

The effect of the ALR on the radial velocity at different axial distances is shown in Fig. 6-b. It can be seen that at $Z=5 \mathrm{~mm}$, there is almost no change in the radial velocity with the variation in the ALR. This means that most of the shroud air is used to accelerate the axial velocity because it does not have a swirl component. However, a slight variation in radial velocity with ALR is observed at longer axial distances due to the change of the axial velocity component.

\subsection{Drop Size Distribution}

Figure 7 shows the effect of the ALR on the mean drop size at different axial distances with a constant fuel flow rate of $0.1687 \mathrm{~kg} / \mathrm{min}$. The smallest droplets are concentrated at the central region of the spray due to being governed by the high inertia and acceleration of the larger droplets positioned in the periphery. SMD increases gradually in further radial position up to a certain distance, which represents the maximum axial velocity, and then shows an almost constant value with a slight decay. This is more profound in longer axial distance where the swirling motion of the spray forms the spatial structure. With increasing the shroud air intensity, the concentration of small droplets is located in a narrower width while the maxima of the mean size at the spray edge decreases. The former is a cause of the entrained air and the former can be attributed to the higher shear layer between air and fuel leading to the enhancement of atomization phenomena along with the evaporation of the small droplets takes place easily at higher ALR (Sommerfeld and Qiu 1998). SMD profile at an axial distance of $28 \mathrm{~mm}$ can clearly 


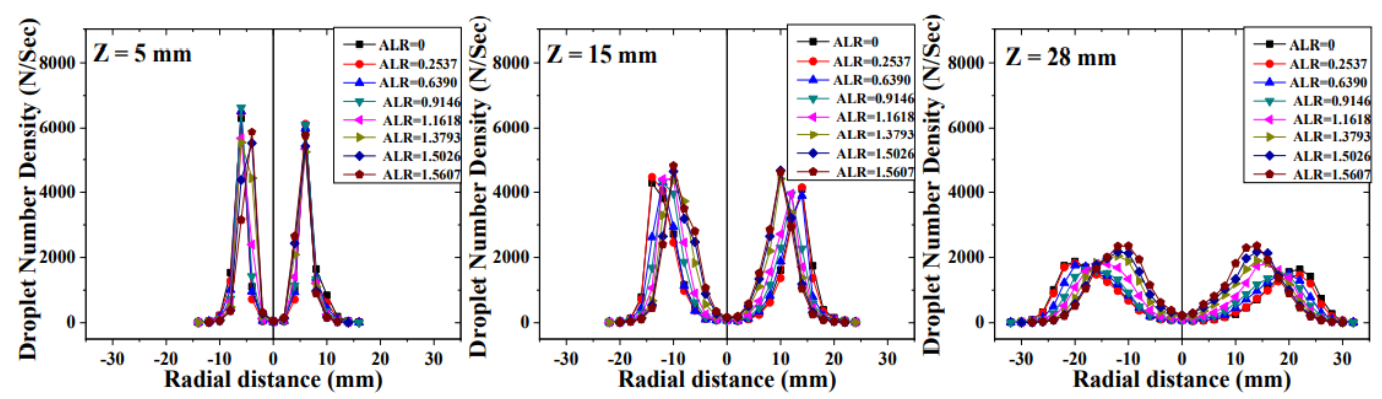

Fig. 8. Droplet number density profile with change of ALR and axial distance.

demonstrate a minimum of $15 \mathrm{~mm}$ shift in the spray width throughout the tested ALR range agreeing with the spray angle dependence on ALR. It is also seen from the figure that the mean droplet size at a radial positioncoinciding with the peak of number density slightly decreases with increasing downstream distance from the nozzle tip due to the evaporation of the droplets and shifting the size class to a larger cluster. The relative velocity increases with the air pressure due to the increase of the air density. This decreases the mean drop size in the central downstream region implies to a decrease in volume flux which is substantially in good agreement with the distribution of number density (Lee and Rho 2000).

The droplet number density indicates the liquid sheet disintegration and the droplet generation process through secondary disintegration. The effect of the droplet number density at different axial distances is shown in Fig. 8. The number density first decreased with increasing ALR, but started to increase after ALR $=0.9146$. This seems to be due to the suppression of the spread of the spray radially when the amount of shroud air is small, thus causing the droplet to coalescence. However, the shroud air promotes the secondary disintegration and evaporation of the droplet to some extent.

\subsection{Weighted Mean SMD}

The WMSMD is a statistical value to show the global mean diameter of the cross section of spray at any desired axial level. It is calculated by Eq. 2. It is essential to select a proper ALR for a certain gas turbine engine application for ideal engine performance. WMSMD is used as a single parameter to characterize global spray quality. WMSMD can be calculated using the equation below:

$$
\text { GSMD }=\frac{\sum_{\mathrm{r}=1}^{\mathrm{r}=\mathrm{R}} \mathrm{SMD}_{\mathrm{r}} \times \mathrm{n}_{\mathrm{r}}}{\sum \mathrm{n}_{\mathrm{r}}}
$$

where $n$ is the total valid count of droplets for each measured point, $r$ is the radial distance of each measurement point and $R$ is the radius of the spray. Several researchers (Lee et al. 2003; Rho et al. 1998; Jedelsky et al. 2009; Jedelsky and Jicha 2014; Tratnig and Brenn 2010; Moradi 2013) investigated the effect of ALR on WMSMD. Most of which focused on a higher range of ALR which doesn't cover the transitional regime of ALR effect. They agree on the effect of shroud air ALR in a higher range that linearly enhances the atomization quality. Jedelsky et al. (2009) used an effervescent atomizer to show that the WMSMD peaked at a certain ALR and then gradually decreased with further increasing ALR for every injection pressure. However, Fig. 9 illustrates the matter in a high resolution of low ALR where a change in trend is observed. The kinetic energy of the gas flow is used as a source of atomization to induce the disintegration of the bulk liquid into ligaments that consequently break up into droplets (Ghadimi and Nowruzi 2016). Shafaee et al. (2011) showed that by increasing the surrounding air flow the atomization regime changes as the weber number increases.

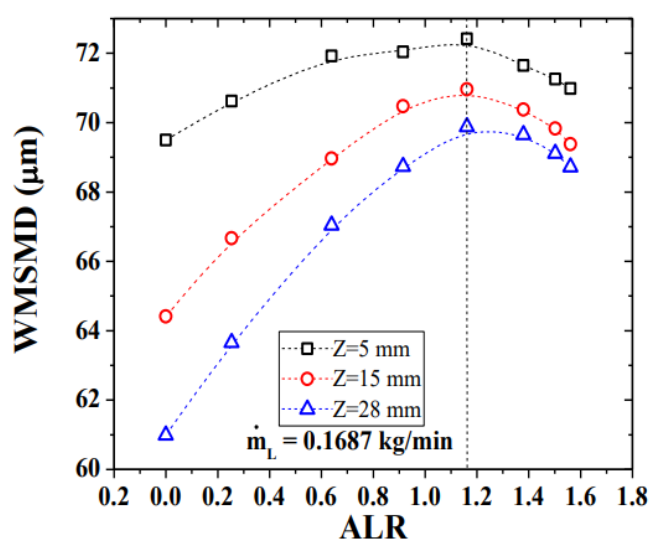

Fig. 9. Weighted mean SMD as a function of ALR for different axial distances.

The WMSMD increases sharply with increases in the ALR up to 1.1618 and then decreases slightly with further increases in the ALR. The reason for the larger WMSMD at lower ALR is that the small droplets evaporate easily at a lower ALR, which causes the disappearance of small droplets from the spray boundary. Then, comparatively large droplets remain in the spray, which causes an increase in the WMSMD. Another reason is the collisions that occur between two or more droplets as the spray droplet moves to the center of the spray due to the increased axial velocity component. Collision is the main mechanism attributed in secondary atomization (Gorokhovski et al. 2009). When the ALR reaches 1.1618 , the WMSMD starts to decrease slightly with 
an increase in the ALR. The reason behind this phenomenon is that at a high ALR, the momentum of the shroud air is enough to cause the secondary disintegration of the droplets (Stapper and Samuelsen 1990). This regime is reported as the increase of weber number, shear stress and leading to faster break up and smaller droplets.

\section{CONCLUSION}

The effect of the low ALR range on the characteristics of the spray generated from a pressure-swirl duplex nozzle using Jet A-1 fuel and prevention of nozzle tip contamination was investigated experimentally. The spray haracteristics were analyzed in terms of flowrate, discharge coefficient, spray structure, spray cone angle, velocity and drop size distribution. The conclusions of this investigation are summarized as follows:

The ALR has neglectable effect on the hydraulic performance of the nozzle. As the ALR increases, the spray angle tends to decrease linearly, and changes by a maximum of $12 \mathrm{deg}$. When the ALR changes from 0 to 1.6, axial component of velocity in the central region increased with increasing ALR. With increasing ALR and moving the measurement level to further axial distances, the spray structure gradually changed from a hollow-cone type to a fullcone type. The swirl intensity is attributed to this change (Vashahi et al. 2019) and a major vertical difference has been reported between hollow-cone and full-cone spray regime (Fuchimoto et al. 2009). Increasing the shroud air intensity forces the larger size drops into the inner region of the spray and this lowers the spray width. The number density profile showed a decay in the periphery hence higher peak moving toward the central region with increasing ALR. Low ALR primarily enhances the evaporation of small droplets leading to larger size class distribution. Higher rate of ALR causes higher turbulent shear layer between air and liquid and accelerates the disintegration of large size droplets into smaller ones accordingly. A uniform drop size distribution is observed near the spray center region. The observation of air-fuel interaction is still of prime interests in this field. A further attempt to better understanding of the air-liquid interaction is suggested through laser diagnostic method such as PLIF to illustrate the multi-phase regional turbulent mechanism.

\section{ACKNOWLEDGEMENTS}

This work was carried out with the support of "Cooperative Research Program for Agriculture Science and Technology Development", Project number: PJ013819022018 Rural Development Administration, Republic of Korea and partially supported by the Hanwha Aerospace Co. Ltd.

\section{REFERENCES}

Chen, S. K., A. H. Lefebvre and J. Rollbuhler (1990). Influence of Geometric Features on the Performance of Pressure-Swirl Atomizers.
Journal of Engineering for Gas Turbines and Power 112, 579-84.

Chen, S. K., A. H. Lefebvre and J. Rollbuhler (1992). Factors Influencing the Effective Spray Cone Angle of Pressure-Swirl Atomizers. Journal of Engineering for Gas Turbines and PowerTransactions of the Asme 114, 97-103.

Chinnaraj, M. and R. Sadanandan (2020). The Effect of Swirling Air-to-Liquid Momentum Ratio on the Spray and Droplet Characteristics. Journal of Applied Fluid Mechanics 13, 82737.

Clare, H., J. A. Gardiner and M. C. Neale (1964). Study of Fuel Injection in Air Breathing Combustion Chambers. Experimental Methods in Combustion Research, 5-20.

Dafsari, R. A., F. Vashahi and J. Lee (2017). Effect of Swirl Chamber Length on the Atomization Characteristics of a Pressure-Swirl Nozzle. Atomization and Spray 27, 1-16.

Dafsari, R. A., F. Vashahi, R. Chandrahasan and J. Lee (2019c). Effect of aviation fuel temperature on refractive index in droplet size measurement using phase Doppler anemometry, Measurement Science and Technology 30. 075203.

Dafsari, R. A., H. J. Lee, J. Han and J. Lee (2019a). Evaluation of the atomization characteristics of aviation fuels with different viscosities using a pressure swirl atomizer. International Journal of Heat and Mass Transfer 145, 118704.

Dafsari, R. A., Lee, H. J., Han, J., Park, D. C. and Lee, J. (2019b). Viscosity effect on the pressure swirl atomization of an alternative aviation fuel. Fuel 240, 179-191

Dafsari, R. A., R. Chandrahasan, C. Ahn and J. Lee. (2020). Effect of Internal Geometry of the Pressure-Swirl Duplex Nozzle on the Atomization Characteristics of Jet A-1 Fuel. Atomization and Spray 30, 55-73.

Dantec-Dynamics. 2011. LDA and PDA reference manual (Denmark).

Dopazo, C. and J Ballester (1994). Discharge Coefficient and Spray Angle Measurements for Small Pressure-Swirl Nozzles. Atomization and Spray 4. 351-367.

Evers, L. W. (1994). Characterization of the transient spray from a high pressure swirl injector. In.: SAE Technical Paper, No. 940188

Ferreira, G., J. A. García, F. Barreras, A. Lozano and E. Lincheta (2009). Design optimization of twin-fluid atomizers with an internal mixing chamber for heavy fuel oils. Fuel Processing Technology 90, 270-78.

Fuchimoto, T., S. Yanase, J. Mizushima and J. Senda. (2009). Dynamics of vortex rings in the spray from a swirl injector. Fluid Dynamics Research 41, 045503.

Geng, L., Y. Wang, J. Wang, Y. Wei and C. F. Lee. 
R. A. Dafsari et al. / JAFM, Vol. 14, No. 3, pp. 877-886, 2021.

(2020). Numerical simulation of the influence of fuel temperature and injection parameters on biodiesel spray characteristics', Energy Science \& Engineering 8, 312-26.

Ghadimi, P. and H. Nowruzi (2016). Effects of Heavy Fuel Oil Blend with Ethanol, n-Butanol or Methanol Bioalcohols on the Spray Characteristics. Journal of Applied Fluid Mechanics, 9(5), 2413-2425.

Gorokhovski, M., J. Jouanguy and A. Chtab Desportes. (2009). Stochastic model of the near-to-injector spray formation assisted by a high-speed coaxial gas jet, Fluid Dynamics Research 41, 035509.

Jedelsky, J. and M. Jicha (2014). Energy considerations in spraying process of a spillreturn pressure-swirl atomizer. Applied Energy $132,485-95$.

Jedelsky, J., M. Jicha, J. Slama and J. Otaha (2009). Development of an effervescent atomizer for industrial burners. Energy \& Fuels 23, 612130 .

Lasheras, J. C., E. Villermaux and E. J. Hopfinger (1998). Break-up and atomization of a round water jet by a high-speed annular air jet. Journal of Fluid Mechanics 357, 351-79.

Lee, K. H., C. S. Lee, B. G. Kim and H. Y. Jeong. (2003). An investigation of design parameter and atomization mechanism for air shrouded injectors', KSME International Journal 17, 751-57.

Lee, S. G. and B. J. Rho (2000). Atomization characteristics in pneumatic counterfiowing internal mixing nozzle. KSME International Journal 14, 1131-42.

Lee, S. G., K. K. Song and B. J. Rho (2002). Investigation of turbulent spray disintegration characteristics depending on the nozzle configuration. KSME International Journal 16, $572-79$.

Lee, S. G. (2008). Effects of ALR and configuration ratio on turbulent structures in swirling flows', Journal of Mechanical Science and Technology 22, 1237-43.

Lefebvre, A. H. and V. G. McDonell (2017). Atomization and sprays. CRC press.

Li, X. R. S. and Tankin (1991). Spray behavior in nonswirling and swirling annular air flows, Atomization and Spray 1, 319-36.

Liu, Z. M., J. Y. Lin, H. L. Zheng and Y. Pang. (2020). Effect of Viscosities on the Spray Characteristics of Pressure Swirl Nozzle. Journal of Applied Fluid Mechanics 13, 86770.

Mansour, A. and N. Chigier (1990). Disintegration of liquid sheets. Physics of Fluid A: Fluid Dynamics 2(5), 706-19.

Marchione, T., C. Allouis, A. Amoresano and
Federico Beretta. (2007). Experimental Investigation of a Pressure Swirl Atomizer Spray. Journal of Propulsion and Power 23, 1096-101.

Moradi, A. (2013). Theoretical Prediction of Sauter Mean Diameter for Pressure-Swirl Atomizers through Integral Conservation Methods. Arizona State University.

Payri, R., L. Araneo, J. Shakal and V. Soare (2008). Phase doppler measurements: system set-up optimization for characterization of a diesel nozzle. Journal of Mechanical Science and Technology 22, 1620-32.

Pitcher, G., G. Wigley and M. Saffman (1991). Sensitivity of Dropsize Measurements by Phase Doppler Anemometry to Refractive Index Changes in Combusting Fuel Sprays. In, 22747. Berlin, Heidelberg: Springer Berlin Heidelberg.

Ralf, K. and N. S. Bravo (2006). Operation conditions of a phase Doppler anemometer: droplet size measurements with laser beam power, photomultiplier voltage, signal gain and signal-to-noise ratio as parameters. Measurement Science and Technology 17, 221.

Resagk, C., R. du Puits and A. Thess (2003). Error estimation of laser-Doppler anemometry measurements in fluids with spatial inhomogeneities of the refractive index. Experiments in Fluids 35, 357-63.

Rho, B. J., S. J. Kang, J. H. Oh and S. G. Lee (1998). Swirl effect on the spray characteristics of a twin-fluid jet. KSME International Journal 12, 899-906.

Roesler, T. C. and A. H. Lefebvre (1989). Studies on aerated-liquid atomization. International Journal of Turbo and Jet Engines 6, 22130.

Roudini, M. and G. Wozniak (2018). Experimental investigation of spray characteristics of prefilming air-blast atomizers. Journal of Applied Fluid Mechanics 11, 145569.

Shafaee, M., S. A. Banitabaei, M. Ashjaee and V. Esfahanian (2011). Effect of flow conditions on spray cone angle of a two-fluid atomizer. Journal of Mechanical Science and Technology $25,365-69$.

Shtern, V. (2018). Mechanisms of jet instability: role of deceleration. Fluid Dynamics Research 50, 051408 .

Som, S., A. I. Ramirez, D. E. Longman and S. K. Aggarwal (2011). Effect of nozzle orifice geometry on spray, combustion, and emission characteristics under diesel engine conditions. Fuel 90, 1267-76.

Sommerfeld, M. and H. H. Qiu (1998). Experimental studies of spray evaporation in turbulent flow', International Journal of Heat and Fluid Flow $19,10-22$.

Stapper, B. E. and G. S. Samuelsen (1990). An 
R. A. Dafsari et al. / JAFM, Vol. 14, No. 3, pp. 877-886, 2021.

experimental study of the breakup of a twodimensional liquid sheet in the presence of coflow air shear. In 28th Aerospace Sciences Meeting 461. Reno, Nevada.

Tratnig, A. and G. Brenn (2010). Drop size spectra in sprays from pressure-swirl atomizers. International Journal of Multiphase Flow 36, 349-63.

Vashahi, F., R. A. Dafsari, Sh Rezaei, J. K. Lee and B. J. Baek (2019). Assessment of steady VOF
RANS turbulence models in rendering the internal flow structure of pressure swirl nozzles. Fluid Dynamics Research 51, 045506.

Vashahi, F. and J. K. Lee (2018). Insight into the Dynamics of Internal and External Flow Fields of the Pressure Swirl Nozzle. Atomization and Spray 28, 1001-28. 